\title{
Novel role of pancreatic differentiation 2 in facilitating self-renewal and drug resistance of pancreatic cancer stem cells
}

A P Vaz ${ }^{1,5}$, M P Ponnusamy ${ }^{1,5}$, S Rachagani ${ }^{1}, \mathrm{P} \mathrm{Dey}^{1}$, A K Ganti ${ }^{2,3}$ and S K Batra ${ }^{*, 1,4}$

${ }^{1}$ Department of Biochemistry and Molecular Biology, University of Nebraska Medical Center, Omaha, NE, USA; ${ }^{2}$ Department of Internal Medicine, VA Nebraska Western lowa Health Care System, University of Nebraska Medical Center, Omaha, NE, USA; ${ }^{3}$ Division of Oncology-Hematology, Department of Internal Medicine, University of Nebraska Medical Center, Omaha, NE, USA and ${ }^{4}$ Buffet Cancer Center, Eppley Institute for Research in Cancer and Allied Diseases, University of Nebraska Medical Center, Omaha, NE, USA

Background: Cancer stem cells (CSCs) contribute towards disease aggressiveness and drug resistance. Specific identification of CSC maintenance genes and targeting can improve the efficiency of currently available treatment modalities. Pancreatic differentiation 2 (PD2) has a major role in the self-renewal of mouse embryonic stem cells. In the present study, we investigated the role of PD2 in pancreatic CSCs.

Methods: Characterisation of CSCs and non-CSCs from mouse models, pancreatic cancer cells and human tissues by CSC and self-renewal marker analysis using confocal assay. Effect of PD2 knockdown in CSCs (after gemcitabine treatment) was studied by immunoblot and apoptosis assays.

Results: A subpopulation of cells displayed PD2 overexpression in mouse (Kras ${ }^{\mathrm{G} 12 \mathrm{D}}$; Pdx1-Cre and Kras ${ }^{\mathrm{G} 12 \mathrm{D}}$; $\operatorname{Trp} 53^{\mathrm{R} 172 \mathrm{H} /+} ; \mathrm{Pdx1-}$ $\mathrm{Cre}$ ) and human pancreatic tumours, which co-express CSC markers. Cancer stem cells exhibited elevated expression of PD2 and self-renewal markers, such as Oct3/4, Shh and $\beta$-catenin. Gemcitabine treatment maintained the CSC population with simultaneous maintenance of PD2 and CSC marker expression. Knockdown of PD2 in CSCs resulted in reduced viability of cells and enhanced apoptosis along with abrogated expression of CD133 and MDR2.

Conclusions: Our results suggest that PD2 is a novel CSC maintenance protein, loss of which renders the CSCs more susceptible to drug-induced cell death.

Stem cells with cancerous properties are widely known as cancer stem cells (CSCs). These CSCs constitute a small proportion of the tumour mass and are found within many human tumours including colon (O’Brien et al, 2007), brain (Singh et al, 2004), breast (Al-Hajj et al, 2003), prostate (Collins et al, 2005), pancreatic (Li et al, 2007) and ovarian cancers (Szotek et al, 2006). Although the existence of CSCs in all tumours is unclear, the quest for CSCs is still intriguing. For a cell to be designated as a CSC, it must possess distinctive properties, such as the ability to regenerate tumours, promote metastasis, cause aggressive cancers and, most importantly, it should be capable of self-renewal (Reya et al, 2001). In addition, CSCs through their drug efflux mechanisms can make the tumour cells resistant to various drugs (Vaz et al, 2013). Failure to target this particular cell population has made the current therapeutic strategies inefficient and consequently tumour recurrence is observed in most patients with advanced stage cancers even after an initial response to treatment. Therefore, considerable research efforts have been directed towards the identification of specific CSC markers in different cancers for therapeutic targeting.

\footnotetext{
*Correspondence: Dr SK Batra; E-mail: sbatra@unmc.edu
}

${ }^{5}$ These authors contributed equally to this work. 
To date, several CSC markers such as CD24, CD34, CD44, CD117, ESA and CD133 have been identified (Al-Hajj et al, 2003; Szotek et al, 2006; Ma et al, 2007; O'Brien et al, 2007; Ferrandina et al, 2008). Cancer stem cells exhibit deregulated self-renewal pathways such as Wnt, Shh and Notch signalling (Reya et al, 2001; Ivanova et al, 2006; Ponnusamy and Batra, 2008). In this regard, the importance of our recent finding is that pancreatic differentiation 2 (PD2) functions as a key regulator of self-renewal in mouse embryonic stem cells (mESCs) through interaction with Oct3/4 (Ponnusamy et al, 2009). In our previous study, a novel PD2 gene (accession number AJ401156) was identified in the 19q13.2 amplicon of pancreatic cancer cells via differential screening analysis (Moniaux et al, 2006). Later, it was discovered that PD2 is the human homologue of the yeast RNA polymerase II-associated factor 1 and is part of the human PAF (hPAF) complex, which consists of other subunits, namely hLeo1, hCtr9, parafibromin/ hCdc73 and hSki8 (Zhu et al, 2005; Moniaux et al, 2006). Further, our study revealed that the overexpression of this gene in the immortalised NIH3T3 cells led to the oncogenic transformation of these cells (Moniaux et al, 2006). In addition, our previous studies also demonstrated the specific roles of PD2/Paf1 in cell cycle progression and chromatin structure remodelling in pancreatic cancer cells (Moniaux et al, 2009; Dey et al, 2011).

In the present study, we demonstrated the novel role of PD2 in CSC maintenance. Our results demonstrate specific expression of PD2 in CSC populations of pancreatic cancer after characterisation of the CSC phenotype by in vitro and in vivo analysis. Furthermore, isolated CSCs were found to exhibit drug resistance, which is impaired upon knockdown of PD2 with simultaneous alteration in the CSC phenotype, and reduction in CD133 and $M D R 2$ gene expression. Overall, these results suggest that $P D 2$ may have a role in self-renewal and drug resistance of CSCs.

\section{MATERIALS AND METHODS}

Genetically engineered pancreatic cancer animal model. Mouse pancreatic cancer progression models were developed by crossing different transgenic mice (Kras ${ }^{\mathrm{G} 12 \mathrm{D}}, \mathrm{Pdx} 1$-Cre and Trp5 $33^{\mathrm{R} 172 \mathrm{H} /+}$ ) to generate a composite mouse strain carrying the following genotype: KC: $\mathrm{Kras}^{\mathrm{G} 12 \mathrm{D}}$; Pdx-Cre and KPC: $\mathrm{Kras}^{\mathrm{G} 12 \mathrm{D}}$; $\operatorname{Trp} 53^{\mathrm{R} 172 \mathrm{H} /+}$; and Pdx1-Cre. Their contemporary littermate controls were also generated. The generated composite double-transgenic (KC: K-ras ${ }^{\mathrm{G} 12 \mathrm{D}}$; Pdx-Cre) animals develop PanINs at 9 weeks of age and it progresses to advanced stages of cancer between 40 and 50 weeks of age (Rachagani et al, 2012); whereas the tripletransgenic composite animals (KPC: K-ras ${ }^{\mathrm{G} 12 \mathrm{D}}$; $\operatorname{Trp} 53^{\mathrm{R} 172 \mathrm{H} /+}$; Pdx1-Cre) develop PanINs at 5 weeks of age and it progresses to pancreatic ductal adenocarcinoma between 20 and 25 weeks of age. The KC (40th and 50th weeks) and KPC (20th and 25th weeks) animals were euthanised and the resected part of the tumour was used for CSCs isolation and the remaining half was fixed in formalin for immunohistochemical studies. We confirmed the presence of tumours by routine hematoxylin and eosin staining and the tumour sections were processed for immunofluorescence studies for PD2 and CSC markers expression. Throughout the experiment, animals were provided with food and water ad libitum and subjected to a 12-h dark/light cycle. Animal studies were performed in accordance with the US Public Health Service 'Guidelines for the Care and Use of Laboratory Animals' under an approved protocol by the University of Nebraska Medical Center Institutional Animal Care and Use Committee.

Cell culture maintenance. Pancreatic cancer (SW1990, MiaPaca and $\mathrm{BxPC} 3$ ) cell lines were procured from American Type Culture Collection (ATCC) (Manassas, VA, USA) and cell lines were propagated in a humidified atmosphere containing $5 \% \mathrm{CO}_{2}$ at $37^{\circ} \mathrm{C}$ and cultured in Dulbecco's modified Eagle's medium (DMEM) supplemented with $10 \%$ fetal bovine serum (FBS) and antibiotics (penicillin and streptomycin). After purchase from ATCC, we have frozen all these cell lines in early passage numbers to precede the experiments.

Isolation of side population (SP) and non-side population (NSP) from cancer cell lines. To determine whether pancreatic cancer cell lines contain candidate CSC populations, Hoechst 33342 dye (a fluorescent DNA-binding dye) has been used to sort the SP cells by flow sorting (Szotek et al, 2006). SP cells can actively pump out the Hoechst 33342 dye, and hence exhibit low fluorescence as compared with the non-SP cells. As only SW1990 cells showed a considerable SP, this cell line was used for further studies. In parallel, verapamil, a calcium channel blocker that reverses the multidrug resistance, was used to ensure that the isolated cells were purely SP cells.

CSC-specific culture. Both SP and NSP cells were cultured in gelatinised tissue culture dishes in a stem cell-specific medium containing DMEM (GIBCO, Grand Island, NY, USA) and F12 supplemented with $10 \%$ embryonic stem (ES)-specific FBS (Invitrogen, Carlsbad, CA, USA), L-glutamine (GIBCO), $1000 \mathrm{U} \mathrm{ml}^{-1}$ LIF (Sigma, St Louis, MO, USA), bFGF (Invitrogen) and Pen/Strp. Two different conditions were maintained for both SP and NSP cells. Initially, we maintained both SP and NSP fractions for 1 day in $10 \%$ FBS-containing DMEM media for the cells to acclimatise and then subsequently replaced it with stem cell-specific medium. We cultured SP cells in stem cell-specific media and NSP cells in $10 \%$ FBS-containing DMEM media because NSP cells did not grow well in stem cell-specific conditions initially but it grew well in DMEM media. Two days before collecting the lysate, the NSP cells were grown in stem cell-specific media. Hence, NSP and SP cells were grown in both DMEM and stem cell-specific media to isolate RNA and protein for further processing.

RNA isolation and RT-PCR. Total cellular RNA was extracted from SP and NSP cells using the RNAeasy kit (Qiagen, Valencia, CA, USA) and processed for reverse transcription. The expression of PD2 and MDR2 was performed by PCR using specific primers (PD2 FP 5'-TTCCTCGGATCAGGCGTCCC-3' PD2 RP 5'-CTGG GACTCAGTCACTGTCACTA-3'; MDR2 FP 5'-AGGATGGAAG CTCACCCTTGTGA-3', MDR2 RP 5'-GAAAGCTATCACAGTC CTGATGGCC-3'; CD133 FP 5'-CAGAGTACAACGCCAAAC CA-3', CD133 RP 5'-AAATCACGATGAGGGTCAGC-3'). The PCR conditions are as follows: initial denaturation step was at $95^{\circ} \mathrm{C}$ for $5 \mathrm{~min}$, followed by the denaturation step at $95^{\circ} \mathrm{C}$ for $1 \mathrm{~min}$, primer annealing step at $58{ }^{\circ} \mathrm{C}$ for $1 \mathrm{~min}$, extension step at $72^{\circ} \mathrm{C}$ for $1 \mathrm{~min}$, followed by 35 cycles of amplification and the final extension step at $72{ }^{\circ} \mathrm{C}$ for $15 \mathrm{~min}$. PCR reaction products were then separated by electrophoresis using a $2 \%$ agarose gel. Gels were stained using $0.5 \mu \mathrm{g} \mathrm{ml}^{-1}$ of ethidium bromide and illuminated with UV light. GAPDH was used as an internal control gene.

Knockdown of PD2 using specific siRNA. The human PD2 region was targeted with specific siRNA (sequence $5^{\prime}$-AACAG GUUCGUCCAGUACAAA- $3^{\prime}$ ). Synthetic sense and antisense oligonucleotides (Dharmacon, Lafayette, CO, USA) were annealed in $100 \mathrm{~mm}$ potassium acetate, $30 \mathrm{~mm}$ HEPES-KOH $(\mathrm{pH} 7.4)$ and $2 \mathrm{~mm}$ magnesium acetate for $1 \mathrm{~min}$ at $90^{\circ} \mathrm{C}$ and $1 \mathrm{~h}$ at $37^{\circ} \mathrm{C}$ and frozen. Oligonucleotides were transfected into cells with TransITTKO (Mirus, Madison, WI, USA) in accordance with the supplier's recommendations. Gemcitabine $(2 \mu \mathrm{M})$ treatment was carried out for 20 days on PD2 knockdown and scramble cells.

Immunoblot assay. SP and NSP cells were processed for protein extraction and western blotting using standard procedures. Briefly, the cells were washed twice with PBS and lysed in RIPA buffer (50 mm Tris- $\mathrm{HCl}, \mathrm{pH}$ 7.4; 0.25\% Na-deoxycholate; 1 mm EDTA; 

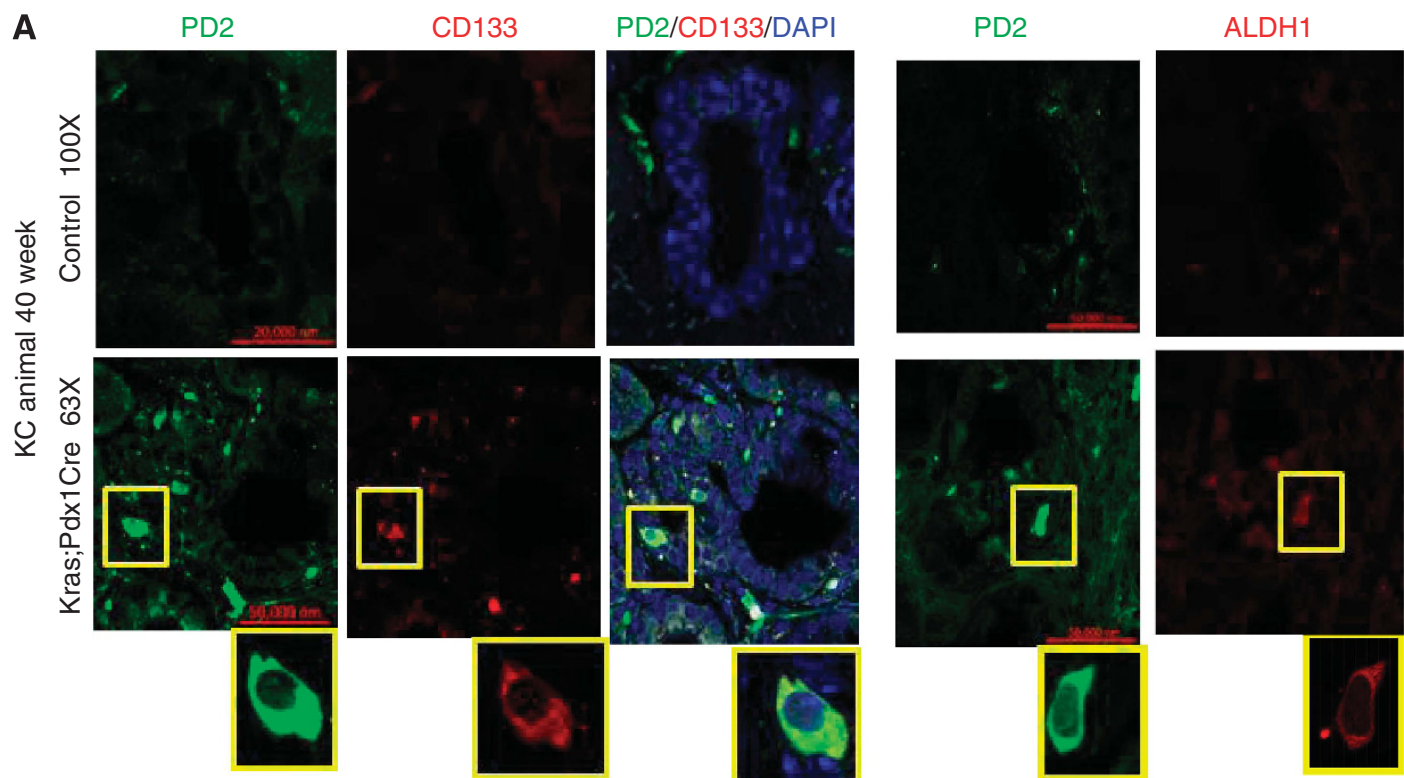

PD2/ALDH1/DAPI
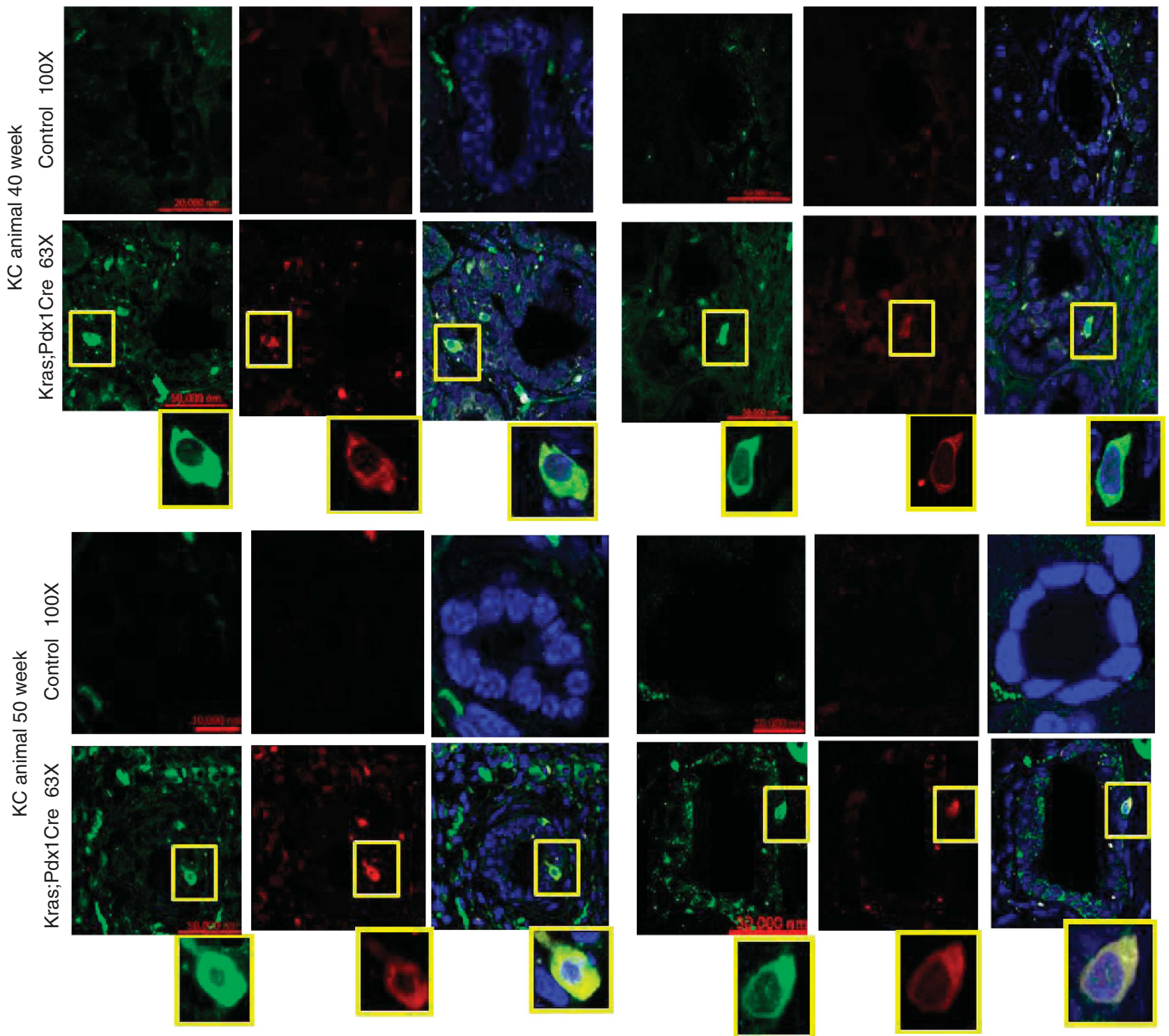

B
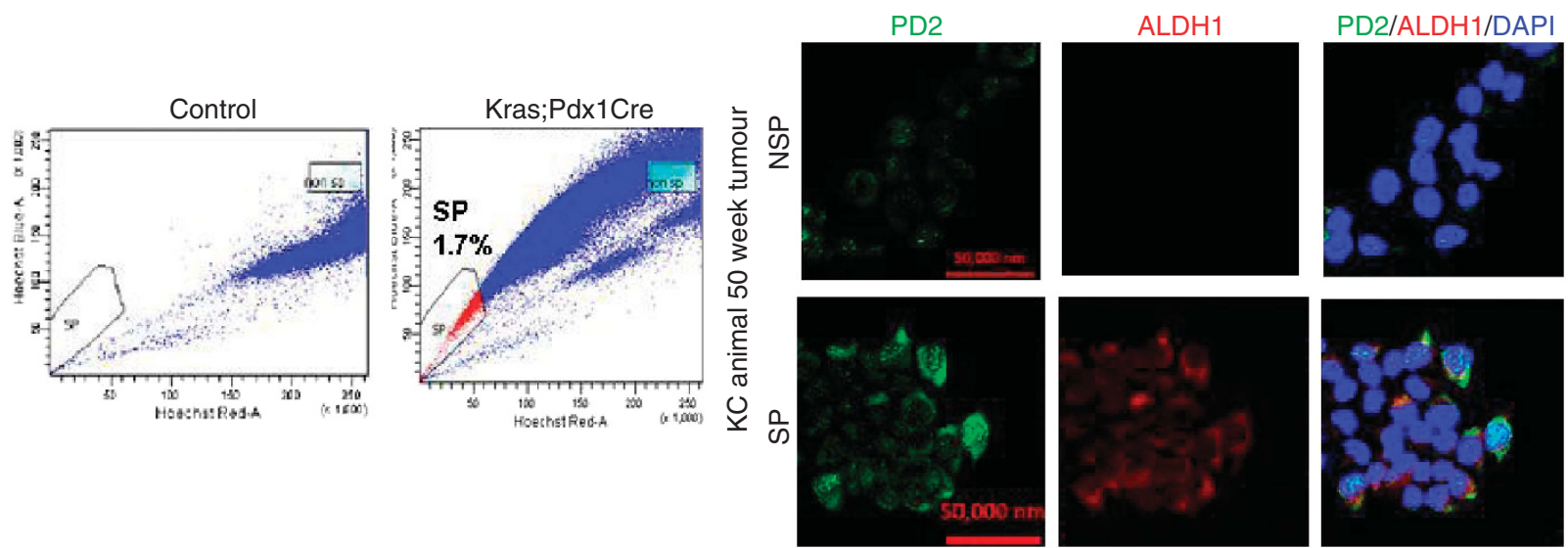

Figure 1. Expression of PD2 in double-transgenic mouse pancreatic cancer samples. (A) Overexpression of PD2 along with CD133 and ALDH1 in the 40th and 50th weeks of Kras-driven mouse pancreatic tumours. The control pancreas showed no expression in ductal cells. The highlighted box shows the zoomed image of single-cell staining. (B) FACS analysis was performed using Hoechst 33342 staining in Kras-driven mouse PCdriven cells. Kras; $\mathrm{Pdx} 1 \mathrm{Cre}$ animal cells showed $1.7 \%$ of SP cells compared with control animals. Confocal images showed the overexpression of PD2 along with ALDH1 in isolated SP cells compared with NSP cells. DAPI was used as a nuclear counter staining. 
$150 \mathrm{~mm} \mathrm{NaCl}$; 1\% NP-40), supplemented with $5 \mathrm{~mm}$ Na3VO4, $5 \mathrm{~mm} \mathrm{NaF}$ and $1 \mathrm{~mm}$ phenylmethylsulphonyl fluoride and stored at $4{ }^{\circ} \mathrm{C}$. Subsequently, the cell lysates were spun at 15000 r.p.m. for $20 \mathrm{~min}$ at $4{ }^{\circ} \mathrm{C}$ and the supernatants were collected. The proteins were resolved by using 10\% acrylamide;bisacrylamide gels and transferred onto the PVDF membrane. The membranes were blocked in 5\% non-fat dry milk in PBS for at least $1 \mathrm{~h}$ and then incubated with primary antibodies (anti-PD2, anti-Cdc73, anti-Leo1, anti-Ctr9, anti-Ski8, anti-ALDH1 (aldehyde dehydrogenase 1), antiCD133, anti-Oct $3 / 4$, anti- Shh and anti- $\beta$-actin) (diluted in 3\% BSA in PBS) and left overnight at $4{ }^{\circ} \mathrm{C}$. Then the membranes were washed $(4 \times 10 \mathrm{~min})$ with PBST (phosphate-buffered saline and $0.1 \%$ Tween 20) at room temperature and probed with 1:2000 diluted horseradish peroxidase-conjugated anti-mouse or anti-rabbit secondary antibodies for $1 \mathrm{~h}$ at room temperature and washed $4 \times 10 \mathrm{~min}$ with PBST. The signal was detected with an ECL chemiluminescence kit (Thermo Scientific, Waltham, MA, USA).

Immunofluorescence analysis by confocal microscopy. Cells were plated onto sterile round cover slips (CIR 18-1 Fisher brand 12-545-10, Fisher Scientific International, Hampton, NH, USA) and grown in 12-well plates for $24 \mathrm{~h}$. Cells were fixed in acetone/ methanol $\left(1: 1\right.$; pre-chilled to $\left.-20^{\circ} \mathrm{C}\right)$ and permeabilised with $0.1 \%$ Triton X-100 in PBS. Then the cells were washed in PBS and blocked with $10 \%$ goat serum for $1 \mathrm{~h}$ and washed with PBS. Next, the cells were incubated with primary antibody rabbit-PD2 $(1: 100$ in $1 \times$ PBS), rabbit-ALDH1 (1:100), rabbit-Shh $(1: 100)$, mouseOct $3 / 4 \quad(1: 100)$, rabbit- $\beta$-catenin $(1: 300)$ and rabbit-CD133 $(1: 100)$ for $1 \mathrm{~h}$ for isolated cells and overnight for tissue sections. The cells and tissue sections were washed with PBST four times (10 min each) and incubated with fluorescent-tagged secondary antibodies-both FITC and Texas-red tagged (for $30 \mathrm{~min}$ ) at room temperature and washed four times with PBST. For the tissue sections, we followed the same procedure as mentioned previously after removing paraffin using xylene and hydrating the section using decreasing grades of alcohol (100\% to $20 \%)$. Finally, cover slips were mounted with vectashield mounting medium containing DAPI (VECTOR, Burlingame, CA, USA).

Apoptosis assay. For this assay, a total of $0.5 \times 10^{6} \mathrm{SW} 1990-\mathrm{SP}$ cells were seeded per well in a six-well plate. These cells were subjected to gemcitabine treatment $(2 \mu \mathrm{M})$ for 7 days, followed by a transient transfection carried out for $72 \mathrm{~h}$ using an siRNA specific against PD2, along with scrambled RNAi. The apoptosis assay was carried out with these gemcitabine-treated and PD2 knockdown cells and control cells for $48 \mathrm{~h}$ using annexin $\mathrm{V}$-fluorescein isothiocyanate apoptosis detection kit (Roche Diagnostics, Indianapolis, IN, USA). After 48 h, the cells were trypsinised, counted and washed with PBS. The level of apoptosis was measured by annexin $\mathrm{V}$ and propidium iodide staining followed by flow cytometry.

\section{RESULTS}

Specific expression of PD2 in mice and human pancreatic tumour samples. Recent evidence demonstrate that human pancreatic CSCs express elevated levels of CD133, CD44, CD24, ESA and ALDH1 markers (Li et al, 2007; Lee et al, 2008; Ponnusamy and Batra, 2008; Li et al, 2009). In another study, it has been shown that the Kras ${ }^{\mathrm{G} 12 \mathrm{D}}$ model carries self-renewing pancreatic CSCs (Shankar et al, 2011). Here, we have analysed the expression of PD2 along with CSC markers (CD133 and ALDH1) in tumours resected from both (KC: K-ras ${ }^{\text {G12D }}$; Pdx1-Cre (40th and 50th weeks) and KPC: K-ras ${ }^{\mathrm{G} 12 \mathrm{D}}$; $\operatorname{Trp} 53^{\mathrm{R} 172 \mathrm{H} /+}$; Pdx1-Cre (20th and 25th weeks)) the mouse models for PC. Hematoxylin and eosin staining of tumour sections clearly showed PanINs as well as areas with well-developed tumours compared with the control pancreas from contemporary littermates of both
KC: K-ras ${ }^{\text {G12D; }}$ Pdx1-Cre (40th and 50th weeks) and KPC: K-ras ${ }^{\mathrm{G} 12 \mathrm{D}}$; Trp53 $3^{\mathrm{R} 172 \mathrm{H} /+}$; Pdx1-Cre (5th, 10th, 15th, 20th and 25th weeks) mouse models (Supplementary Figures 1a and b). We have clearly observed PD2 overexpression along with CD133 and ALDH1 markers only in a specific population of cells (Figure 1A) in 40- and 50-week-old $\mathrm{KC}$ mouse samples compared with agematched control animals. The specificity of antibodies was analysed using different conditions of negative controls such as using only secondary antibody in the absence of primary antibody and also by swapping secondary antibodies (Supplementary Figure 1c) in the same KC mouse tumours. Furthermore, cells overexpressing PD2 also expressed CSC markers (CD133 and ALDH1) in the triple-transgenic KPC samples (25th week) compared with the control samples (20th week) (Figure 2). In addition, we observed $1.7 \%$ CSCs in KC tumour samples, whereas no SP/CSC population was observed in the control samples using Hoeschst33342 dye staining-based FACS analysis (Figure 1B). The isolated CSCs from KC tumour samples showed a clear cobblestone structure, which is a phenotype of CSCs, along with
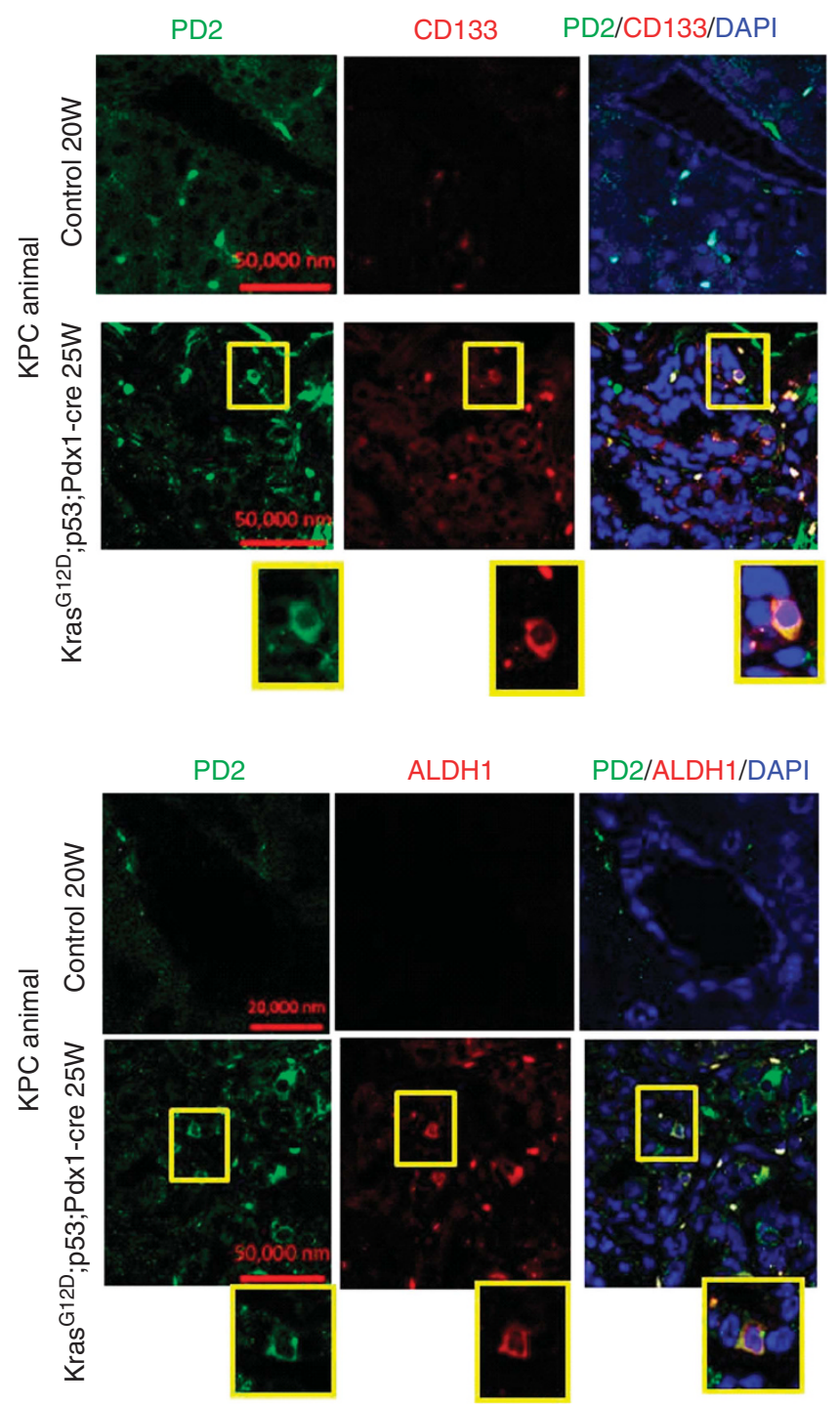

Figure 2. Expression of PD2 in triple-transgenic mouse pancreatic cancer samples. Overexpression of PD2 along with CD133 and ALDH1 in the 25th week of Kras- and p53-driven mouse pancreatic tumours. Control pancreas (20th week) showed no expression in ductal cells. The highlighted box is blown up to show the zoomed image of single-cell staining. 
elevated expression of PD2 and ALDH1 when compared with control cells (Figure 1B). Furthermore, we have also observed increased PD2 expression along with ALDH1 in selected cells within human pancreatic tumour samples (Figure 3A) compared with control samples. These results suggest that PD2 is specifically overexpressed in the CSC population.

Isolation and characterisation of SP and NSP cells from pancreatic cancer cells. Recently, CSCs have been identified as a minor population of cells within the cancer cell population. They can be sorted by flow cytometry based on their capacity to efflux the fluorescent DNA-binding dye, Hoechst 33342. This is owing to the overexpression of the ABCG2 drug resistance protein, a characteristic of cancer stem/progenitor cells (Bunting, 2002; Kim et al, 2002). This population of sorted cells is called the SP and the remaining population is named NSP. In the present study, we analysed the SP and NSP cells in pancreatic cancer cell lines (SW1990, BXPC3 and MiaPaCa) (Supplementary Figure 2a). The SW1990 pancreatic cancer cell line showed $0.2 \%$ of SP cells, isolated by Hoechst 33342 dye using the FACS sorting method. Other cancer cell lines (MiaPaCa and BXPC3) showed minimal or no SP population. In parallel, verapamil (a calcium channel inhibitor that reverses the multidrug resistance) was used to ensure that the isolated cells were purely SP cells (Supplementary Figure 2b).

Isolated SP and NSP cells from SW1990 were grown in vitro under stem cell-specific conditions (details are mentioned in the Materials and Methods section). SP cells showed tight junctions and circular colony formation (Supplementary Figure 2c), whereas NSP cells grew
A

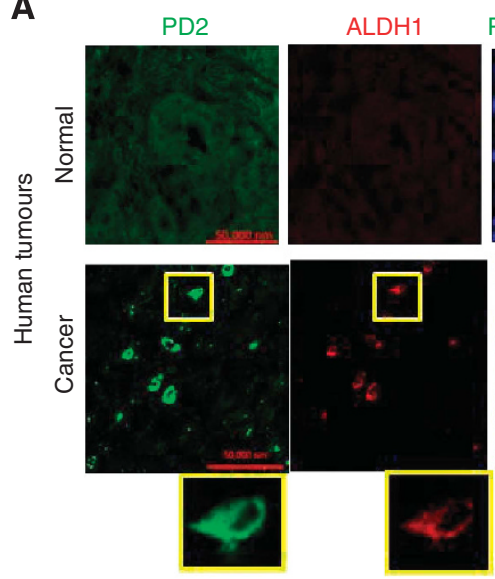

C
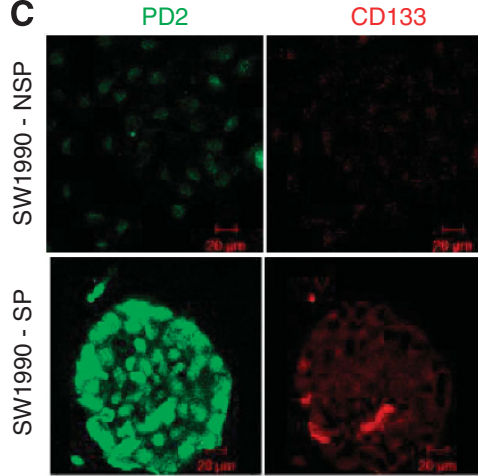

PD2
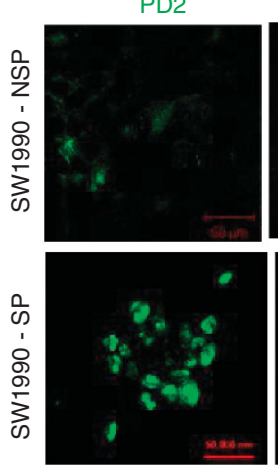

ALDH1
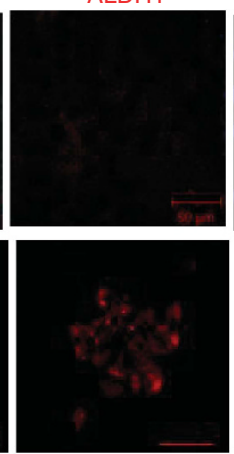

PD2/ALDH1/DAPI
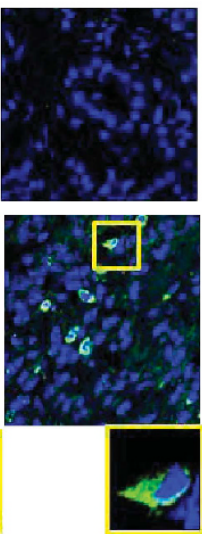

DAPI

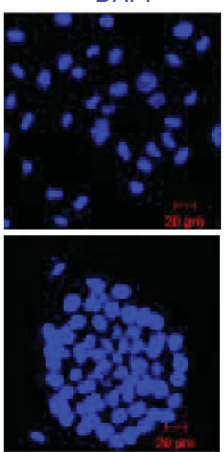

DAPI
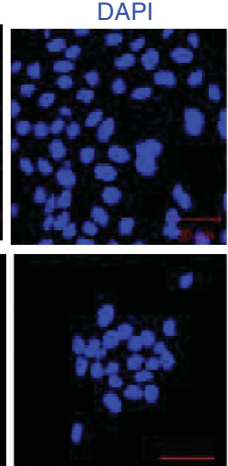

B

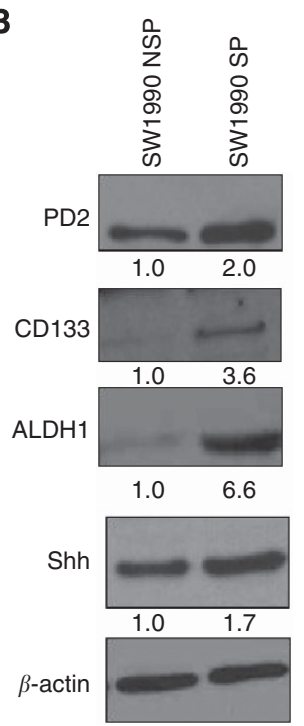

D
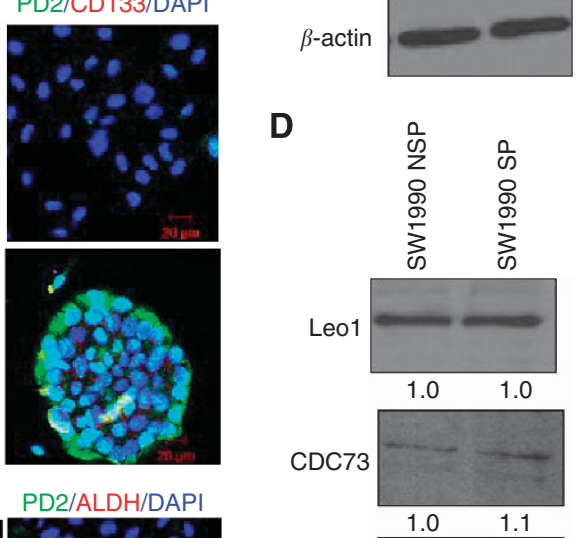

PD2/ALDH/DAPI
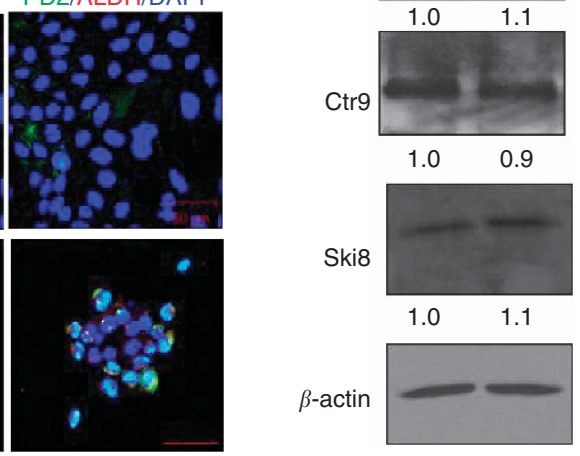

$1.0 \quad 1.1$

$\beta$-actin

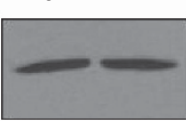

Figure 3. Expression of PD2 and CSC markers. SP and NSP cells were processed for protein extraction and western blotting using standard procedures. (A) Overexpression of PD2 in human pancreatic tumours along with ALDH1 in specific cells. Control tumours did not show specific overexpression of PD2. (B) Western blot analysis showed increased expression of PD2 in isolated SP cells along with cancer stem cell-specific markers (CD133 and ALDH1) and also the self-renewal marker SHH in SW1990-SP cells compared with NSP cells. $\beta$-actin was used as a loading control. Fold change of band intensity is mentioned in the western blot results. (C) Confocal analysis showed increased expression of PD2 (green) along with CSC markers (CD133 and ALDH1, red) in SP cells compared with NSP cells (DAPI-nuclear staining). (D) Western blot analysis showed other PAF complex subunits such as Leo1, Cdc73, Ctr6 and Ski8 did not show any variation of expression in both SP and NSP cells. 
like differentiated cells. Formation of spherical colonies has been reported to be a property of stem/progenitor cells and verifies a high developmental and proliferative potential of SP cells (Engelmann et al, 2008). Interestingly, in our study, we observed an increased number of larger tumourspheres in SP cells compared with NSP cells in pancreatic cancer cell line models (data not shown). This confirms that the isolated SP cells behave like CSCs. Furthermore in vivo tumorigenicity assays were also carried out to validate the CSCs. We observed that the SP cells were highly tumorigenic in nature, and therefore it was used for further analysis (data not shown).

Preferential expression of PD2 and CSC-specific markers in SP cells. Cancer stem cells have been demonstrated to express several universal stem cell markers such as CD133, CD44, CD24, ESA and ALDH1 in different cancers (Ponnusamy and Batra, 2008). Stem cells and CSCs are known to possess the phenomenal property of self-renewal, which is maintained by few specific pathways such as Shh, Wnt and Notch (Ponnusamy and Batra, 2008). These markers were used for the confirmation of the isolated CSC population. In our recent study, we have shown that PD2 is aberrantly expressed in mESCs and maintains the selfrenewal process by interacting with Oct3/4 (Ponnusamy et al, 2009). In this study, we analysed PD 2 along with CSC markers such as CD133, ALDH1, Oct3/4 and Shh in both SP and NSP cells from SW1990 cells. Interestingly, PD2 showed a significantly elevated expression along with CD133, ALDH1 and Shh in
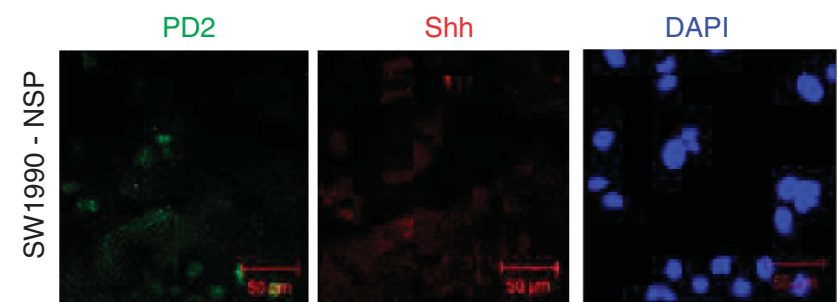

PD2/Shh/DAPI
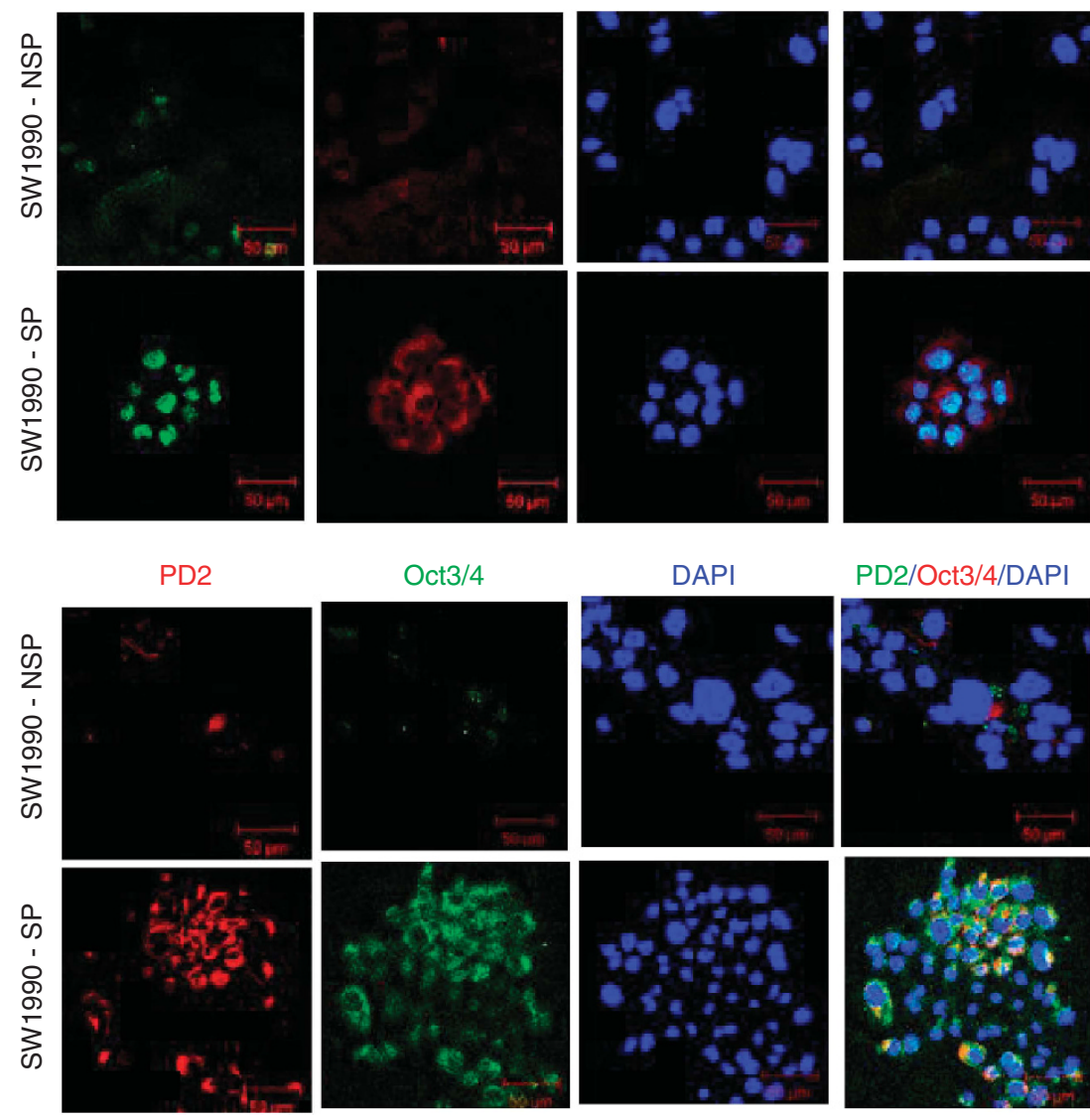

PD2/Oct3/4/DAPI
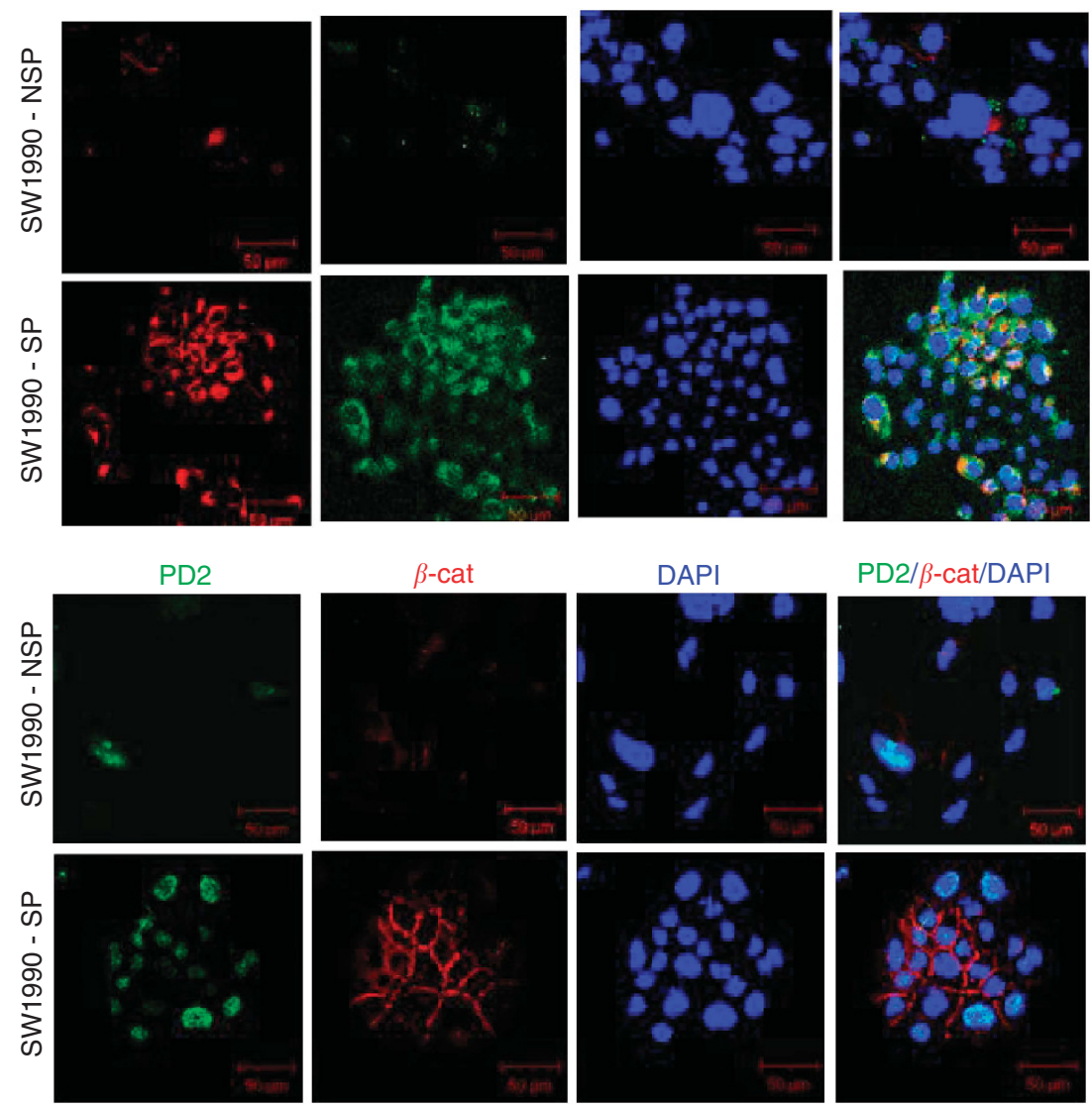

Figure 4. Self-renewal markers in isolated SP cells. Confocal analysis showed a set (Shh, Oct3/4 and $\beta$-catenin) of self-renewal marker expression in SW1990-SP cells. The first panel showed the increased expression of Shh (red) along with PD2 (green) in SP cells compared with NSP cells. The second panel showed the increased expression of Oct3/4 (green) along with PD2 in SP cells compared with NSP cells. The third panel showed the membrane localisation and increased expression of $\beta$-catenin (red) along with PD2 (green) expression. DAPI was used for nuclear staining. 
SW1990-SP cells compared with NSP cells (Figures 3B and C). Other PAF complex subunits such as Leo1, Cdc73, Ctr9 and Ski8 did not show any variation of expression in both SP and NSP cells (Figure 3D). The expression levels of PD2 and ALDH1 were stable up to the third cell passage when maintained under stem cell-specific conditions (data not shown). This suggests that when maintained under stem cell-specific conditions, the isolated CSC population were maintained in the third passage. Our previous studies have shown the sub-cellular localisation of PD2 both in the cytoplasm and nucleus (Moniaux et al, 2009; Dey et al, 2011). These results indicate that PD2 is preferentially upregulated in the pancreatic cancer SP cells compared with the NSP. In addition, self-renewal markers Oct $3 / 4$, Shh and $\beta$-catenin showed significantly elevated expression in SW1990-SP cells compared with NSP cells (Figure 4) by confocal immunofluorescence analysis.
Drug treatment maintains the CSC population and PD2 expression. Cancer stem cells are the population of cells responsible for imparting the drug resistance property to solid tumours, which is leading to tumour recurrence. It has already been established that drug resistance of CSCs is due to the expression of $\mathrm{ABC}$ transporter glycoproteins, which are capable of effluxing the drug out of the cell. To investigate their drug resistance efficiency, we treated SW1990 SP and NSP cells with $2 \mu \mathrm{M}$ gemcitabine for 20 days. Cell death was observed on drug treatment in NSP cells, whereas SP cells maintained their circular colonies and continued to grow even after 4, 10 and 20 days of treatment (Figure 5A). This suggests that isolated SP cells retain their drug resistance property. The expression of PD2 was steadily maintained along with ALDH1 in the gemcitabine $(2 \mu \mathrm{M})$-treated SW1990-SP cells (Figure 5B), suggesting maintenance of CSCs upon drug treatment.

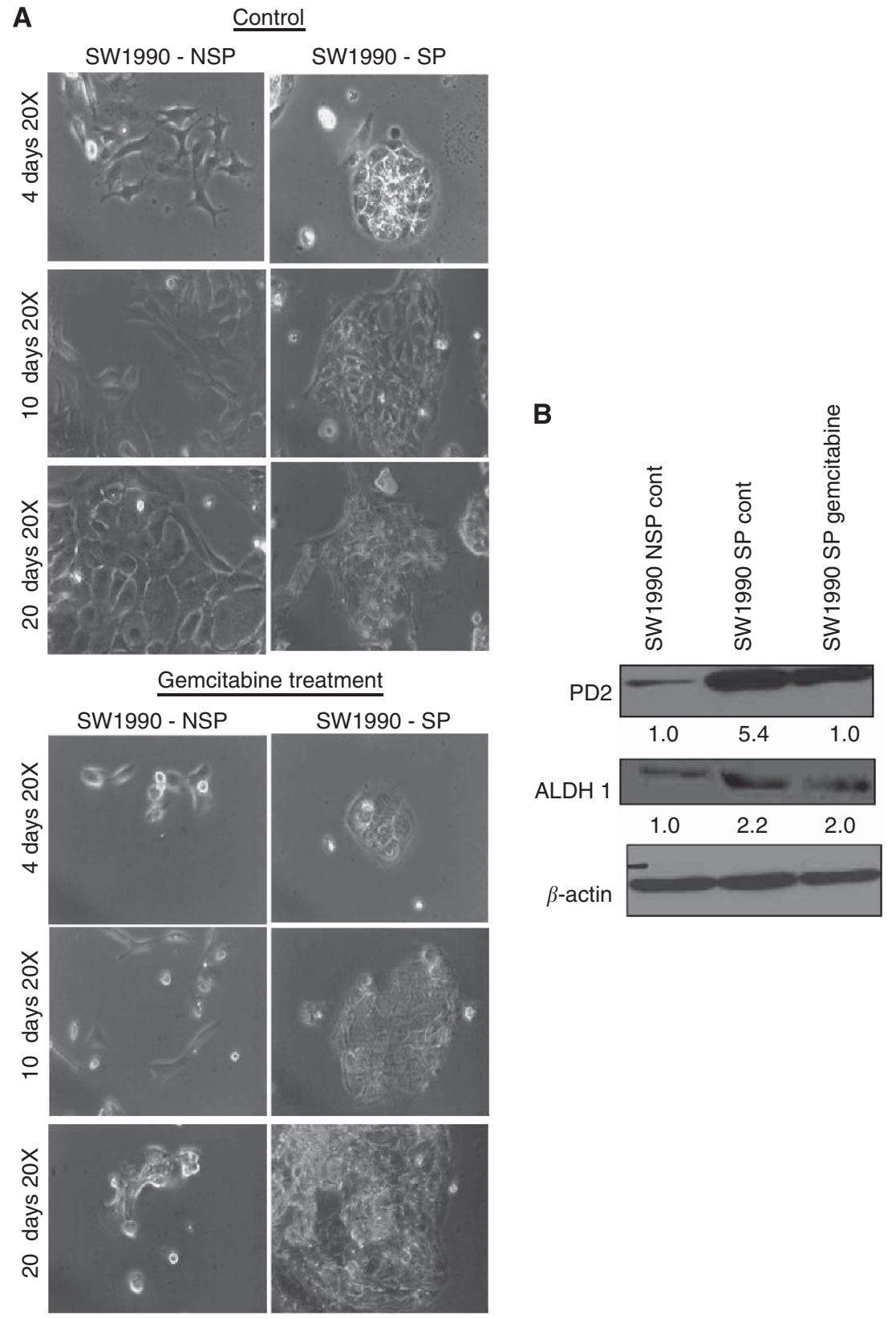

Figure 5. Drug sensitivity of cancer stem cells (SP) and non-cancer stem cells (NSP) on different days of treatment. (A) Gemcitabine (2 $\mu \mathrm{M}$ ) treatment was used for 20 days in both SW1990-SP and NSP cells. SP cells grew well with the characteristic stem cell phenotype upon gemcitabine treatment compared with NSP cells. (B) Western blot analysis showed that the expression of PD2 and ALDH1 is maintained in gemcitabine-treated $\mathrm{SP}$ cells. $\beta$-actin was used as a loading control. Fold change of band intensity is mentioned in the western blot results. 
Knockdown of PD2 affects the CSC phenotype. Seven days of gemcitabine treatment followed by transient knock down (72 h) of PD2 was carried out in SW1990-SP cells. We transiently knock down PD2 using siRNA in SP cells and also treated the knockdown cells with gemcitabine to understand the role of PD2 in drug resistance of SP cells. Our results showed that PD2 knockdown in SP cells resulted in a loss of their CSC phenotype (Figure 6A), leading to apoptosis (SP-SCR-RNAi: $18.8 \%$ and SP-PD2-RNAi: $30.1 \%$ ) on gemcitabine treatment (Figure 6B). Further, analysis of PD2, CSC and drug-resistant markers in gemcitabine-treated PD2 knockdown SP cells resulted in impaired CSC marker (CD133) and drug-resistant gene (MDR2) expression compared with control cells (Figure 6C). These results indicate that PD2 is involved in the maintenance of the CSC population and controlling the drug resistance process.

\section{DISCUSSION}

Cancer stem/initiating cells have the potential to propagate the tumour and may be accountable for cancer development, progression, metastasis and tumour relapse. Identification of specific molecules that maintain CSCs and targeting these molecules will therefore provide us with an important tool to combat cancer. The central study in this paper is to investigate the expression and role of PD2 in pancreatic CSCs. The specific overexpression of PD2 along with CSC markers in tumours resected from genetically engineered models for pancreatic cancer suggest that PD2 may be an important molecule in CSCs. Cancer stem cells with their self-renewal property were recently shown in a Kras-driven pancreatic tumour mouse model (Shankar et al, 2011). The nature of these CSCs isolated using Hoechst 33342 dye was
A

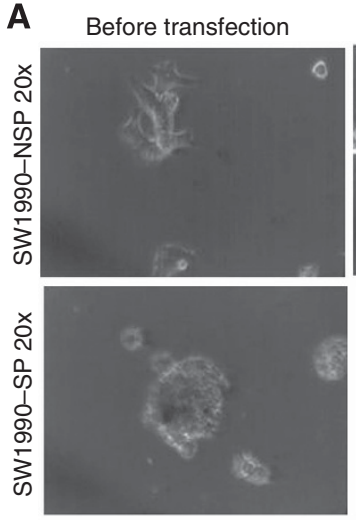

B
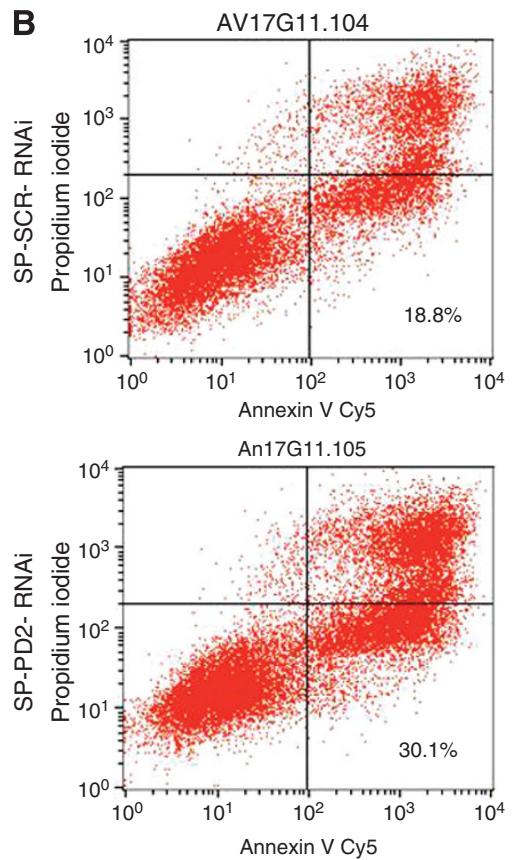

Control/scramble RNAi
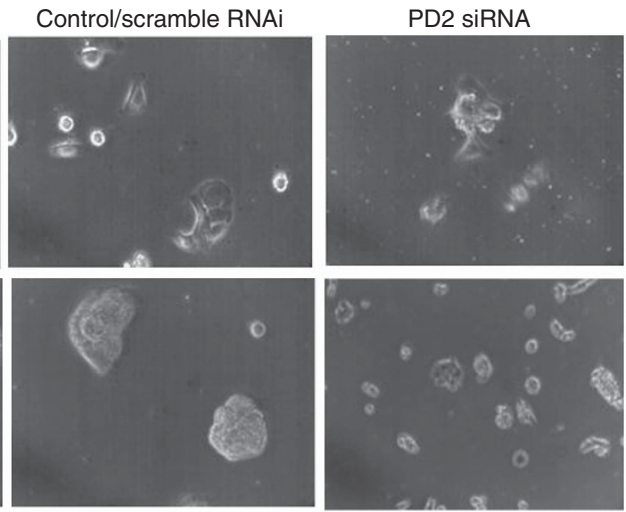

C IRRA

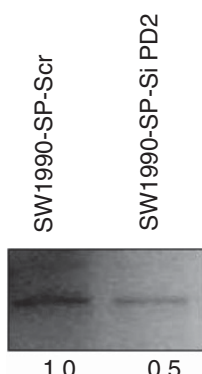

PD2

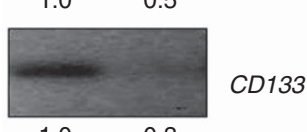

$1.0 \quad 0.3$
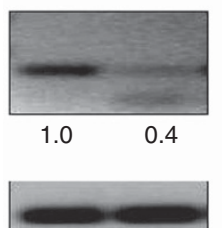

MDR2

GAPDH

$\underline{\text { Protein }}$

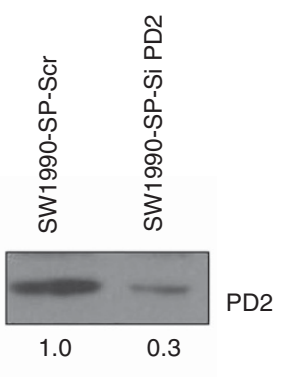

CD133
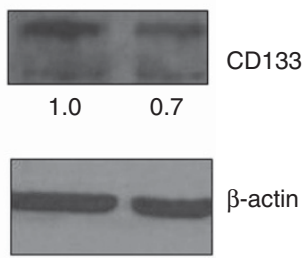

Figure 6. Knockdown of PD2 with drug treatment in SP cells. (A) Seven days of gemcitabine treatment followed by transient knockdown (72h) of PD2 was carried out in SW1990-SP cells. Knockdown of PD2 with simultaneous gemcitabine treatment in cancer stem cells (SP) decreased the viability of SP cells and changed its phenotype. (B) FACS-apoptosis analysis with annexin $\mathrm{V}$ and propidium iodide staining showed an increased percentage of cell death (30.1\%) in PD2 knockdown SP cells along with gemcitabine treatment compared with control cells (18.8\%). (C) RT-PCR results showed that knockdown of PD2 downregulates the levels of CD133 and the multidrug resistance 2 (MDR2) gene. Western blot results showed a decrease in the expression of CD133 protein in PD2 knockdown cells. GAPDH and $\beta$-actin served as an expression control. Fold change of band intensity is mentioned in the RT-PCR and western blot results. 
confirmed using in vitro tumorsphere assays and in vivo animal assays (data not shown). There are many well-established methods that demonstrate the isolation of CSCs from different cancers using Hoechst 33342 dye and surface markers (Al-Hajj et al, 2003; Collins et al, 2005; Dean et al, 2005; Szotek et al, 2006; Dalerba et al, 2007; Mimeault et al, 2007; Engelmann et al, 2008; Ferrandina et al, 2008; Ponnusamy and Batra, 2008; Marsden et al, 2009). The main limitation of using Hoechst dye is its toxicity to cells; but if the concentration and incubation time has been standardised toxicity to cells could be minimised. Small differences in cell densities, dye concentrations and staining timings may affect the phenotype of the SP cells. Despite these limitations, we preferred to use the Hoechst 33342 dye exclusion assay as it overcomes the barrier of using diverse CSC markers for isolation.

PD2 is a newly discovered self-renewal stem cell factor in mESCs (Ponnusamy et al, 2009) and is involved in the self-renewal process by interacting with the ESC marker Oct3/4 (Ponnusamy et al, 2009). It is well established that self-renewal is a common and important property of all types of stem cells including CSCs (Reya et al, 2001; Dalerba et al, 2007; Ponnusamy and Batra, 2008). Similarly, other groups have shown that knockdown of PAF complex proteins alter the ESC fate (Ding et al, 2009). Though PD2 is a member of the hPAF complex, it works exclusively (independent of the other subunits) in mESC maintenance (Ponnusamy et al, 2009). The recent report on PD2 in mESCs has shown that the heterozygous knockout of PD2 in mESCs had no effect on the expression level of other PAF components; however, their expression was altered when a homologous knockdown of both PD2 alleles was performed in the NIH3T3 cells (Ponnusamy et al, 2009). This indicates that there is synchronised activity of PD2 in differentiated cells as opposed to the desynchronised activity of PD2 in undifferentiated cells such as stem cells.

Our earlier studies have demonstrated that PD2 is significantly overexpressed in poorly differentiated pancreatic cancer cells compared with well-differentiated cells (Moniaux et al, 2006). In the present study, we correlated the expression of PD2 with the maintenance of the CSC population isolated from pancreatic cancer cells. The expression of PD2 was found to be significantly enriched in SP cells isolated from pancreatic cancer cells; however, other PAF complex subunits did not show any variation in expression in SP cells. This suggests that PD2 has a role independent to the PAF complex. Similarly, in our previous study we have shown that the PAF complex is not involved in coordinated events in mESCs (Ponnusamy et al, 2009). Further, the analysis of stem cell-specific markers (ALDH1, CD133 and CD44) was correlated with PD2 expression, suggesting that isolated SP cells maintain the cancer stem-like characters. In addition, the analysis of self-renewal markers Oct $3 / 4$ and Shh showed an increased level of expression in isolated SP cells compared with NSP cells. This in parallel with PD2 overexpression prompts us to propose that this molecule may be involved in the self-renewal process of CSCs.

The complete mechanism(s) of drug resistance and tumour relapse, as well as the expression of different genes involved in drug resistance and their regulation in CSCs still remains to be elucidated. Understanding the underlying mechanism would provide considerable insight for combating CSCs'-associated drug resistance in different cancers. It has been reported that breast cancer patients undergoing chemotherapy exhibit an increase in the percentage of $\mathrm{CD} 44^{+} \mathrm{CD} 24^{- \text {low }}$ cancer cells due to the chemoresistance property of cancer-initiating cells

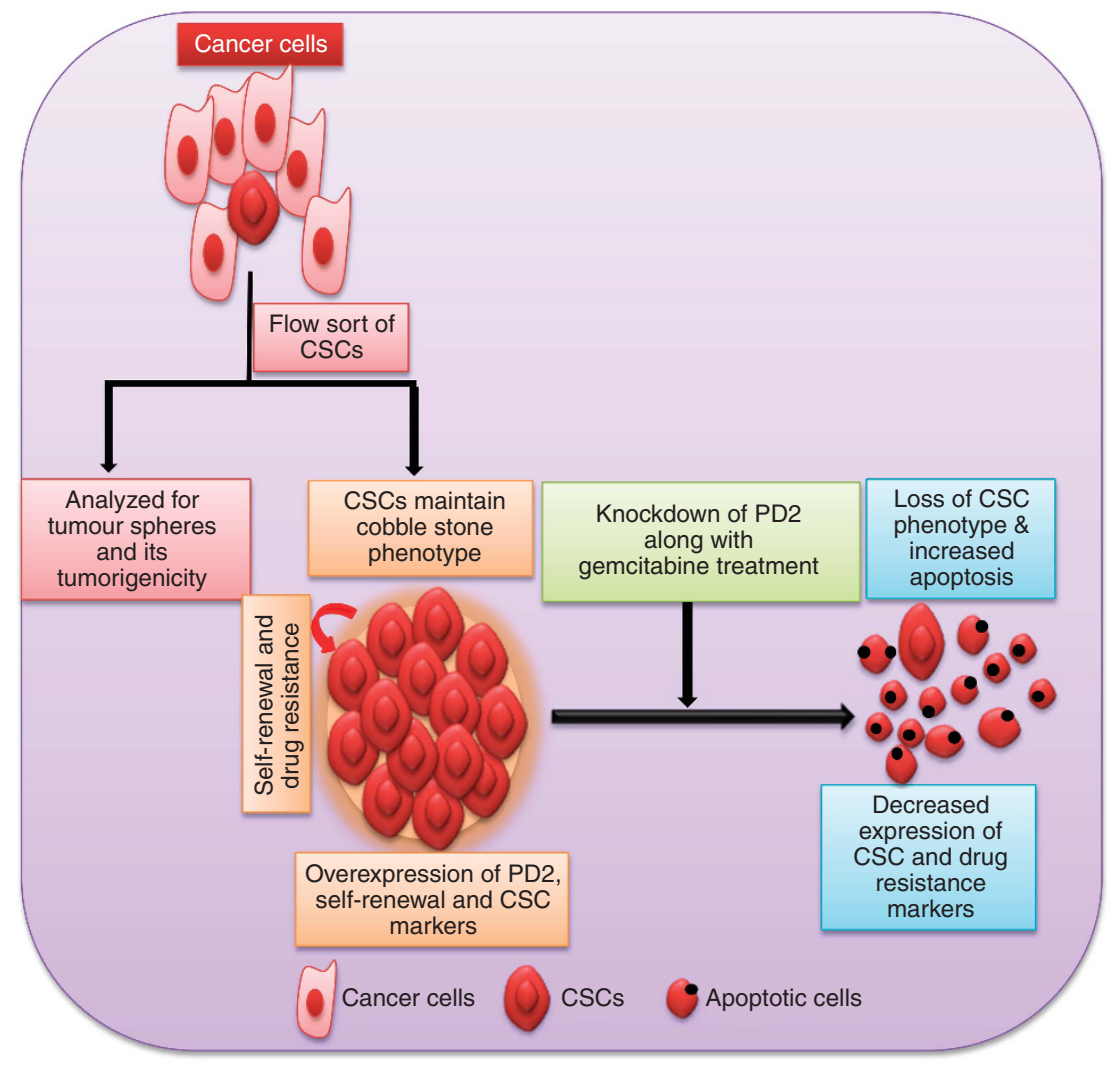

Figure 7. Schematic illustration for the role of PD2 in CSCs. The isolated cancer stem cells by flow sort method were analysed for the tumorigenicity and tumourspheres formation. Isolated CSC populations overexpress PD2 and maintain the self-renewal and drug resistance property. The knockdown of PD2 in CSCs along with drug treatment reduces the viability of CSCs. Furthermore, PD2 inhibition changed the CSC phenotype and downregulated CSC and drug resistance markers. Overall, the diagram demonstrates the role of PD2 in the maintenance of CSCs and drug resistance. 
(Zhou et al, 2009). Similarly, in PC patients, the CD $44^{+} \mathrm{CD} 24^{+}$ cell population increases due to chemotherapy (Jimeno et al, 2009).

Gemcitabine is a nucleoside analogue that is widely used as a chemotherapeutic agent to treat several cancers and is presently the most effective agent against pancreatic cancer. In our study, gemcitabine-treated SP cells survived for 20 days in contrast to the NSP cells, suggesting that the isolated SP population retained their drug resistance property. The expression of PD2 and ALDH1, a drug resistant and CSC-specific marker, was also maintained in SP cells during the period of drug treatment. However, a transient knockdown of PD2 in the SP cells results in increased apoptosis and reduced self-renewal markers' expression was observed. This suggests that PD2 may also be involved in the process of drug resistance in the CSC population. As downregulation of PD2 also showed a reduced expression of other markers such as CD133 and MDR2, this suggests that PD2 is involved in the maintenance of the CSC population and imparts drug resistance. A recent study in our laboratory showed colocalisation of PD2 with MLL1 (mixed lineage leukaemia 1), a histone methyltransferase required for MDR regulation (Huo et al, 2010; Dey et al, 2011). As MDR genes are critical in conferring drug resistance, the probable involvement of PD2 in regulating the expression of these $M D R$ genes, either directly (chromatin enrichment) or indirectly (using MLL1) have generated great interest and warrant further investigation.

In conclusion, the CSC/SP fraction maintains tumorigenesis and the drug resistance property along with an enriched expression of PD2 and other CSC-specific markers (ALDH1, CD133 and CD44) and self-renewal markers (Oct $3 / 4$ and Shh). Furthermore, the inhibition of PD2 leads to a loss of the CSC phenotype and decreased expression of CD133 and MDR2. Although other CSC markers exist, PD2 stands out as a novel marker owing to its ability to maintain the cellular morphology, drug resistance and selfrenewal property of CSCs (Figure 7). Future studies need to dissect the mechanism behind the regulation of drug resistance and selfrenewal genes by PD2. Overall, our study suggests that PD2 has an important role in the maintenance of CSCs and is also involved in drug resistance. Most importantly, the identification of CSCs with the specific maintenance marker PD2 would provide critical information for advancing towards the long-term goal of developing novel therapeutic strategies to reduce the incidence of tumour recurrence in cancer patients.

\section{ACKNOWLEDGEMENTS}

We acknowledge the invaluable technical support from Kavita Mallya. We acknowledge the support extended by Victoria Smith, Charles Kuzynski, PhD and Philip Hexley, $\mathrm{PhD}$ of the flow cytometry facility at UNMC. The UNMC Flow Cytometry Research Facility is administrated through the Office of the Vice Chancellor for Research and supported by state funds from the Nebraska Research Initiative (NRI) and The Fred and Pamela Buffet Cancer Center's National Cancer Institute Cancer Support Grant. Major instrumentation has been provided by the Office of the Vice Chancellor for Research, The University of Nebraska Foundation, the Nebraska Banker's Fund, and by the NIH-NCRR Shared Instrument Program. We also thank Janice A Taylor and James R Talaska, of the confocal laser scanning microscope core facility at UNMC, for their support. This work was supported by grants from the National Institutes of Health (EDRN UO1CA111294, SPORE P50CA127297, TMEN U54CA163120 and R03 CA167342) VA Career Development Award and the Elsa U Pardee Foundation (2013).

\section{CONFLICT OF INTEREST}

The authors declare no conflict of interest.

\section{AUTHOR CONTRIBUTIONS}

Conception and design: MP Ponnusamy, AP Vaz and SK Batra; development of methodology: MP Ponnusamy and AP Vaz; acquisition of data: MP Ponnusamy, AP Vaz, S Rachagani and P Dey; analysis and interpretation of data: MP Ponnusamy, AP Vaz, AK Ganti and SK Batra; writing, review and/or revision of the manuscript: MP Ponnusamy, AP Vaz and SK Batra; administrative, technical or material support: SK Batra and AK Ganti; study supervision: MP Ponnusamy and SK Batra.

\section{REFERENCES}

Al-Hajj M, Wicha MS, ito-Hernandez A, Morrison SJ, Clarke MF (2003) Prospective identification of tumorigenic breast cancer cells. Proc Natl Acad Sci USA 100(7): 3983-3988.

Bunting KD (2002) ABC transporters as phenotypic markers and functional regulators of stem cells. Stem Cells 20(1): 11-20.

Collins AT, Berry PA, Hyde C, Stower MJ, Maitland NJ (2005) Prospective identification of tumorigenic prostate cancer stem cells. Cancer Res 65(23): 10946-10951.

Dalerba P, Cho RW, Clarke MF (2007) Cancer stem cells: models and concepts. Annu Rev Med 58: 267-284.

Dean M, Fojo T, Bates S (2005) Tumour stem cells and drug resistance. Nat Rev Cancer 5(4): 275-284.

Dey P, Ponnusamy MP, Deb S, Batra SK (2011) Human RNA polymerase II-association factor 1 (hPaf1/PD2) regulates histone methylation and chromatin remodeling in pancreatic cancer. PLoS One 6(10): e26926.

Ding L, Paszkowski-Rogacz M, Nitzsche A, Slabicki MM, Heninger AK, de V I, Kittler R, Junqueira M, Shevchenko A, Schulz H, Hubner N, Doss MX, Sachinidis A, Hescheler J, Iacone R, Anastassiadis K, Stewart AF, Pisabarro MT, Caldarelli A, Poser I, Theis M, Buchholz F (2009) A genome-scale RNAi screen for Oct 4 modulators defines a role of the Paf1 complex for embryonic stem cell identity. Cell Stem Cell 4(5): 403-415.

Engelmann K, Shen H, Finn OJ (2008) MCF7 side population cells with characteristics of cancer stem/progenitor cells express the tumor antigen MUC1. Cancer Res 68(7): 2419-2426.

Ferrandina G, Bonanno G, Pierelli L, Perillo A, Procoli A, Mariotti A, Corallo M, Martinelli E, Rutella S, Paglia A, Zannoni G, Mancuso S, Scambia G (2008) Expression of CD133-1 and CD133-2 in ovarian cancer. Int J Gynecol Cancer 18(3): 506-514.

Huo H, Magro PG, Pietsch EC, Patel BB, Scotto KW (2010) Histone methyltransferase MLL1 regulates MDR1 transcription and chemoresistance. Cancer Res 70(21): 8726-8735.

Ivanova N, Dobrin R, Lu R, Kotenko I, Levorse J, DeCoste C, Schafer X, Lun Y, Lemischka IR (2006) Dissecting self-renewal in stem cells with RNA interference. Nature 442(7102): 533-538.

Jimeno A, Feldmann G, Suarez-Gauthier A, Rasheed Z, Solomon A, Zou GM, Rubio-Viqueira B, Garcia-Garcia E, Lopez-Rios F, Matsui W, Maitra A, Hidalgo M (2009) A direct pancreatic cancer xenograft model as a platform for cancer stem cell therapeutic development. Mol Cancer Ther 8(2): 310-314.

Kim M, Turnquist H, Jackson J, Sgagias M, Yan Y, Gong M, Dean M, Sharp JG, Cowan K (2002) The multidrug resistance transporter ABCG2 (breast cancer resistance protein 1) effluxes Hoechst 33342 and is overexpressed in hematopoietic stem cells. Clin Cancer Res 8(1): 22-28.

Lee CJ, Dosch J, Simeone DM (2008) Pancreatic cancer stem cells. J Clin Oncol 26(17): 2806-2812.

Li C, Heidt DG, Dalerba P, Burant CF, Zhang L, Adsay V, Wicha M, Clarke MF, Simeone DM (2007) Identification of pancreatic cancer stem cells. Cancer Res 67(3): 1030-1037.

Li C, Lee CJ, Simeone DM (2009) Identification of human pancreatic cancer stem cells. Methods Mol Biol 568: 161-173.

Ma S, Chan KW, Hu L, Lee TK, Wo JY, Ng IO, Zheng BJ, Guan XY (2007) Identification and characterization of tumorigenic liver cancer stem/ progenitor cells. Gastroenterology 132(7): 2542-2556.

Marsden CG, Wright MJ, Pochampally R, Rowan BG (2009) Breast tumorinitiating cells isolated from patient core biopsies for study of hormone action. Methods Mol Biol 590: 363-375. 
Mimeault M, Hauke R, Mehta PP, Batra SK (2007) Recent advances in cancer stem/progenitor cell research: therapeutic implications for overcoming resistance to the most aggressive cancers. J Cell Mol Med 11(5): 981-1011.

Moniaux N, Nemos C, Deb S, Zhu B, Dornreiter I, Hollingsworth MA, Batra SK (2009) The human RNA polymerase II-associated factor 1 (hPaf1): a new regulator of cell-cycle progression. PLoS One 4(9): e7077.

Moniaux N, Nemos C, Schmied BM, Chauhan SC, Deb S, Morikane K, Choudhury A, Vanlith M, Sutherlin M, Sikela JM, Hollingsworth MA, Batra SK (2006) The human homologue of the RNA polymerase II-associated factor 1 (hPafl), localized on the 19q13 amplicon, is associated with tumorigenesis. Oncogene 25(23): 3247-3257.

O'Brien CA, Pollett A, Gallinger S, Dick JE (2007) A human colon cancer cell capable of initiating tumour growth in immunodeficient mice. Nature 445(7123): 106-110.

Ponnusamy MP, Batra SK (2008) Ovarian cancer: emerging concept on cancer stem cells. J Ovarian Res 1(1): 4.

Ponnusamy MP, Deb S, Dey P, Chakraborty S, Rachagani S, Senapati S, Batra SK (2009) RNA polymerase II associated factor 1/PD2 maintains self-renewal by its interaction with Oct3/4 in mouse embryonic stem cells. Stem Cells 27(12): 3001-3011.

Rachagani S, Torres MP, Kumar S, Haridas D, Baine M, Macha MA, Kaur S, Ponnusamy MP, Dey P, Seshacharyulu P, Johansson SL, Jain M, Wagner KU, Batra SK (2012) Mucin (Muc) expression during pancreatic cancer progression in spontaneous mouse model: potential implications for diagnosis and therapy. J Hematol Oncol 5: 68.

Reya T, Morrison SJ, Clarke MF, Weissman IL (2001) Stem cells, cancer, and cancer stem cells. Nature 414(6859): 105-111.
Shankar S, Nall D, Tang SN, Meeker D, Passarini J, Sharma J, Srivastava RK (2011) Resveratrol inhibits pancreatic cancer stem cell characteristics in human and KrasG12D transgenic mice by inhibiting pluripotency maintaining factors and epithelial-mesenchymal transition. PLoS One 6(1): e16530.

Singh SK, Hawkins C, Clarke ID, Squire JA, Bayani J, Hide T, Henkelman RM, Cusimano MD, Dirks PB (2004) Identification of human brain tumour initiating cells. Nature 432(7015): 396-401.

Szotek PP, Pieretti-Vanmarcke R, Masiakos PT, Dinulescu DM, Connolly D, Foster R, Dombkowski D, Preffer F, Maclaughlin DT, Donahoe PK (2006) Ovarian cancer side population defines cells with stem cell-like characteristics and Mullerian Inhibiting Substance responsiveness. Proc Natl Acad Sci USA 103(30): 11154-11159.

Vaz AP, Ponnusamy MP, Batra SK (2013) Cancer stem cells and therapeutic targets: an emerging field for cancer treatment. Drug Deliv Transl Res 3(2): $113-120$.

Zhou BB, Zhang H, Damelin M, Geles KG, Grindley JC, Dirks PB (2009) Tumour-initiating cells: challenges and opportunities for anticancer drug discovery. Nat Rev Drug Discov 8(10): 806-823.

Zhu B, Mandal SS, Pham AD, Zheng Y, Erdjument-Bromage H, Batra SK, Tempst P, Reinberg D (2005) The human PAF complex coordinates transcription with events downstream of RNA synthesis. Genes Dev 19(14): 1668-1673.

This work is published under the standard license to publish agreement. After 12 months the work will become freely available and the license terms will switch to a Creative Commons AttributionNonCommercial-Share Alike 3.0 Unported License.

Supplementary Information accompanies this paper on British Journal of Cancer website (http://www.nature.com/bjc) 